\title{
COVID 19: A Cause for Pause in Undergraduate Medical Education and Catalyst for Innovation
}

\author{
Elizabeth Southworth ${ }^{1}$ (D) . Sara H. Gleason ${ }^{2}$
}

Accepted: 4 December 2020 / Published online: 22 January 2021

(c) The Author(s), under exclusive licence to Springer Nature B.V. part of Springer Nature 2021

\begin{abstract}
As the world held its breath for news surrounding COVID-19 and hunkered down amidst stay-at-home orders, medical students across the U.S. wondered if they would be called to serve on the front lines of the pandemic. Medical school administrators faced the challenge of protecting learners while also minimizing harm to their medical education. This balancing act raised critical questions in medical education as institutions reacted to changing guidelines. COVID-19 has punctuated already contentious areas of medical education and has forced institutions and organizations to take quick action. From the perspectives of a recent medical school graduate and current resident (ES) and a practicing clinician-educator (SHG), we examine the pandemic's impact on undergraduate medical education through an ethical lens. First, we explore the value of medical education, what drives this value, and how COVID-19 may alter it. We next consider student choice and how shifts toward utilitarianism in healthcare during a pandemic may affect learning and career exploration. Then, we inquire how access to technology may impact the experience of medical students from diverse backgrounds and varied institutions during a rapid shift to socially distanced learning. We identify vulnerabilities for students at several phases of the journey: premedical, preclinical, clinical, and preparation for residency. Finally, we address the hidden curriculum of COVID-19, its potential erosion of empathy among current medical students, and possible long-term consequences for future physicians and patients.
\end{abstract}

Keywords COVID-19 $\cdot$ Undergraduate medical education $\cdot$ Licensing $\cdot$ Health education

Elizabeth Southworth

soelizab@med.umich.edu

1 Department of Obstetrics and Gynecology, University of Michigan L4001 Women's Hospital, 1500 East Medical Center Drive, Ann Arbor, MI 48109-0276, USA

2 Department of Psychiatry and Human Behavior, University of Mississippi Medical Center, 2500 North State Street, Jackson, MS 39216, USA 


\section{Introduction}

As the world held its breath for news surrounding COVID-19 and hunkered down amidst stay-at-home orders, medical students across the U.S. wondered if they would be called to serve on the front lines of the pandemic. While some students eagerly embraced new responsibilities, others were apprehensive about bringing the virus home (Gallagher and Schleyer 2020). Medical school administrators faced the challenge of protecting learners while also minimizing interference with their medical education. This balancing act raised critical questions in medical education as institutions reacted to changing guidelines. Preclinical coursework was offered online when possible. For students on clinical rotations, patient care was transitioned to telehealth or replaced with virtual cases (Rose 2020). As COVID-19 became the new normal, the medical education community set forth guidelines to maintain progress for students nearing transitions and testing milestones. Many of these early guidelines left implementation to individual institutions, underscoring the variability that characterizes undergraduate medical education (Whelan et al. 2020). COVID-19 has punctuated already contentious areas of the curriculum and has forced institutions and organizations to take quick action. We must consider consequences of a "learning as we go" approach to medical education, just as we have considered consequences of this approach to clinical outcomes (Rubin et al. 2020; Vearrier and Henderson 2020).

From the perspectives of a recent medical school graduate and current resident (ES) and a practicing clinician-educator (SHG), we examine the pandemic's impact on undergraduate medical education through an ethical lens. To be clear, we find ourselves asking more questions than we can answer, yet we hope thereby to raise worthwhile talking points in the inevitable debates and decisions now confronting our profession. We examine, first, the value of medical education, what drives this value, and how COVID-19 may alter it. We next consider student choice and how shifts toward utilitarianism in healthcare during a pandemic may affect learning and career exploration. Then, we inquire how access to technology may impact the experience of medical students from diverse backgrounds and varied institutions during a rapid shift to socially distanced learning. We identify vulnerabilities for students at several phases of the journey: premedical, preclinical, clinical, and preparation for residency. Finally, we address the hidden curriculum of COVID-19, its potential to exacerbate the erosion of empathy among current medical students, and possible long-term consequences for future physicians and patients. Before we begin, in order to contextualize the pandemic's influence, let's take a look at the state of medical education prior to COVID-19. 


\section{Pre-COVID-19 Medical Education Innovations}

Medical education in the U.S. has suffered growing pains during the last century, particularly the past few decades. With little overhaul since the Flexner Report, ${ }^{1}$ medical education has experienced fragmented innovation, with pockets of medical schools trying new curricula, accelerated preclinical year tracks, and novel teaching technologies (Emanuel 2020). With 172 American Association of Medical Colleges (AAMC) member schools ${ }^{2}$ and 37 American Association of Colleges of Osteopathic Medicine (AACOM) member schools, ${ }^{3}$ the sheer number of programs lends to variability in the medical student experience. Although the Liaison Committee on Medical Education (LCME), the Commission on Osteopathic College Accreditation (COCA), and other organizations promote standardization and establishment of minimal competencies, the individual student's experience is still highly dependent on the local institution. While at the end of four years medical students across the country graduate with an M.D. or a D.O. after their names, the path they took to earn it was highly variable (Association of American Medical Colleges (AAMC, 2019; McOwen et al. 2020). This variability across undergraduate medical education adds a level of complexity, especially during crisis situations. When modifying a complex system, a one-size-fits-all approach does not necessarily work (Tolsgaard et al. 2020).

The medical education establishment and medical students have identified components of undergraduate medical education that warrant revision, including the preclinical experience, the steps of the United States Medical Licensing Exam $^{4}$ (USMLE), and the residency application process (Invitational Conference on USMLE Scoring [InCUS] 2019; Gliatto and Karani 2016). In normal times, change in medical education and licensure is slow, occurring after years of debate and requiring gradual phase-in. A recent example is the move from a three-digit numerical score to pass/fail grading for the USMLE Step 1. While the pass/fail format is open to criticism, many feel the change reduces stress in the preclinical years and facilitates a more holistic review of residency applicants. This change was announced prior to COVID-19, however, and will not be implemented until 2022 at the earliest (Murphy 2020; InCUS 2019).

\footnotetext{
${ }^{1}$ The Flexner Report (Flexner et al., 1910) is a landmark report of medical education in the United States and Canada. Many aspects of the present-day American medical profession stem from the Flexner Report and its findings (Beck 2004; Duffy 2011; Irby et al. 2010).

2 AAMC Who We Are (2020). https://www.aamc.org/who-we-are; AAMC Medical School Members (2020). https://members.aamc.org/eweb/DynamicPage.aspx? webcode=AAMCOrgSearchResult\&orgty pe $=$ Medical $\% 20$ School.

${ }^{3}$ U.S. Colleges of Osteopathic Medicine. https://www.aacom.org/become-a-doctor/u-s-colleges-of-osteo pathic-medicine?utm_expid=.avFKKCTGTnekw7PDvTQ1AA.0\&utm_referrer=https $\% 3 \mathrm{~A} \% 2 \mathrm{~F} \% 2 \mathrm{Fwww}$ .aacom.org\%2Fbecome-a-doctor\%2Fu-s-colleges-of-osteopathic-medicine

${ }^{4}$ The USMLE is owned by two entities: the Federation of State Medical Boards (FSMB) and the National Board of Medical Examiners (NBME). It is composed of Step 1, Step 2 Clinical Skills, Step 2 Clinical Knowledge, and Step 3. Passing scores on Steps 1 and 2 are required for graduation from medical school and to obtain a temporary training medical license. Step 3 is taken during residency and is a prerequisite for full medical licensure and specialty board examinations.
} 
The residency application process has been a focus of reform efforts in the past several years. The American Medical Association (AMA) Reimaging Residency initiative aims to revolutionize the transition from undergraduate to graduate medical education by supporting novel projects and programs with grant funding (AMA 2019). An example is the Right Resident, Right Program, Ready Day One project conducted by the Association of Professors of Gynecology and Obstetrics (APGO) to develop standards for the application and interview processes, create additional metrics to support a holistic review of candidates, and generate a compatibility index to aid students in program selection. This is APGO's response to a disturbing trend of unfilled residency spots and unmatched candidates despite increasing numbers of applications for ObGyn (Association of Professors of Gynecology and Obstetrics 2020; Hammoud et al. 2020; Weissbart et al. 2015). While this initiative is within a single specialty, it may serve as a model for other specialties. Fourth-year medical students feel pressure to apply broadly to residencies despite evidence that a larger number of applications does not improve an individual's match rate. One potential explanation is that applicants lack the proper information to assess their candidacy adequately and to apply strategically to programs.

These are just several examples of critical areas in undergraduate medical education prior to the COVID-19 pandemic. As the pandemic hit and swiftly changed medical education and assessment, many such initiatives faced an accelerated timeline with new demands--and new opportunities-to innovate in a time of crisis.

\section{Value of Undergraduate Medical Education}

A June 2020 editorial in AAMC News \& Insights features the dean of a U.S. institution urging prospective students to apply to medical school despite COVID-19's disruption of the application process. The dean acknowledges that the pandemic is an unprecedented obstacle for applicants, but he asserts the silver lining may be an acceleration of recent holistic trends in admissions which have shifted the focus away from hard measures like the Medical College Admission Test (MCAT) score and grade point average (GPA). He emphasizes that answering the call to become a physician is a noble endeavor, inseparable from humanism, empathy, and social justice. He reminds us that the medical school application process is just one step in a journey that is worth the struggles and the rewards (Kerschner 2020).

Here, we consider how COVID-19 is redefining those struggles and rewards. Should the candidate's decision to attend medical school be a holistic one or one driven by dollars and cents? Is it ethical to encourage others to enter the field when a reliable forecast of return on investment is no longer available? To what extent, however, is it wise or ethical to discourage premed hopefuls during an ongoing pandemic and a time of physician shortages?

For the past two decades, medical students have been shouldering annual tuition increases at least three times the consumer price index (Pettett 2011). As of 2019, the median student debt burden at graduation from medical school was $\$ 200,000$ (Association of American Medical Colleges 2019), with no guarantee of passing licensure tests, being admitted to residency (Boyle 2020), becoming board-certified 
in a specialty, or landing a job. Medical student debt burden and its consequences for the individual and society are matters of national importance and debate (Greysen et al. 2011; Hughes et al. 1991; Jolly 2005; Thomas 2019). COVID-19 has given medical students plenty of time at home to contemplate the cost and value of their education, especially when they have been deprived of a most important feature: interaction with faculty and patients on the wards (Heudebert and Estrada 2018). Class action lawsuits may settle tuition disputes for the 2019-2020 academic year students who were paying tuition and incurring long-term indebtedness for lectures that were not delivered, patients not seen, procedures not done (Martinez 2020; Winter and McGee-Tubb 2020). But future cohorts have fair warning that uncertainty is the new normal: caveat emptor. How does the aspiring medical student appraise the value of education that is currently on the market? Is the virtual medical education of the pandemic era good enough to produce graduates who can succeed in residency?

The idealistic or risk-averse applicant may not be deterred by a high educational mortgage and may instead focus on the benefits of a medical education. Traditionally, these benefits have included the honor of serving humanity and the socioeconomic perks of membership in an elite profession. Prior to COVID-19, the honor and perks were already eroding. Physicians complain of spending more time serving the electronic medical record than serving humanity (Gardner et al. 2019; Woolhandler and Himmelstein 2014). And professional identity is diluted as non-physicians, such as nurse practitioners and physician assistants, enter realms previously dominated by physicians. Generic titles like "provider" or "prescriber" reinforce the view that the role of physician is less a profession and more a trade. This plays out in debates about the role of medical students in clinical rotations during COVID-19. Denying medical students access to bedside instruction during the pandemic has been justified in part because students lack the status of essential worker and they introduce more cost and risk than value to the clinical setting (Menon et al. 2020; Tolsgaard et al. 2020). Contrast this to the early days of the AIDS epidemic when a medical student, fearing accidental exposure to HIV, refused to perform venipuncture on an HIV-positive patient. That student was viewed as shirking a professional obligation (Whalen 1987). As medical students return to the wards for training during the COVID-19 era, how should we respond if they demand exemption from core clinical requirements on the grounds that they are not essential employees and should not be compelled to risk exposure to the virus? Some argue that in-person involvement of medical students with COVID-19 patients should be entirely voluntary (Miller et al. 2020).

Prior to COVID-19, the economic argument for entering medical school was already debatable (Association of American Medical Colleges 2019; Pettett 2011), but at least there was some transparency in the educational experience purchased and the timeline it would follow. In the pandemic era, medical students are paying the same price with no guarantees about the format or quality of the educational product. If the education is substandard, future patients will also pay a heavy price. 


\section{Choice in Undergraduate Medical Education}

One of the most exciting aspects of medical school is exploring various fields and choosing which specialty to pursue. With over thirty specialties and a number of opportunities to subspecialize, finding the best fit is based on many factors including personality, clinical interests, and career and life goals. This individual choice is mutually beneficial as it generally facilitates positive pairings for students and programs alike in the transition to residency. As we have seen in other aspects of healthcare during the pandemic, rationing and allocation of resources to specific specialties over others occurs within a framework that Vearrier and Henderson $(2020)^{5}$ describe as Utilitarian Principlism, in which promoting equity in healthcare takes on a central role.

Utilitarianism in the context of medical education and career exploration may mean that students are influenced by current healthcare needs and projected implications for various specialties. We cannot assume that the most competitive specialties will maintain top rank as we advance. If pandemic restrictions continue to upend scheduling of elective procedures (Khullar et al. 2020), the financial structure of U.S. hospitals will be turned on its head and currently elite and lucrative specialties may become less desirable for trainees. If the pandemic continues to make unrelenting demands on less remunerative and/or more hazardous frontline specialties-family medicine, emergency medicine, internal medicine, infectious diseases, critical care, nephrology, palliative care, just to name a few--we may see two contradictory trends. First, due to their risky and exhausting conditions of employment, these residencies and fellowships are likely to witness downturns in recruitment; conversely, because of their essential nature in the crisis, those same specialities may see higher salaries in order to keep their positions filled and therefore higher trends in enrollment. We cannot count on altruistic tendencies to offer a pipeline of talent to carry us through a protracted pandemic; compensation will play a role.

How might the opportunity to choose a specialty be affected if the needs of the nation call for increases in the frontline workforce? Some limitations on choice are already in place based on the number of funded residency positions (Boyle 2020); however, if the economic effects of COVID-19 persist, would increased funding for frontline specialties be warranted? In the face of labor shortages during COVID-19, some healthcare systems have promoted early medical school graduation and fasttrack licensure (Flotte et al. 2020; Harvey 2020). The idea of reducing the duration of medical school is not a new one. The current four-year undergraduate medical curriculum is a legacy of the 1910 Flexner Report and is considered obsolete by many. It was designed at a time when the fund of medical knowledge was smaller, students graduated from medical school ready to function as general practitioners, and graduate medical education was briefer (Cangiarella et al. 2016). Recognizing that most students choose their specialty by the end of the third year, some question the value of an additional year. The last year of medical school is the least

\footnotetext{
5 For further discussion on Utilitarian Principlism, please refer to Vearrier and Henderson's article in this issue of the HEC Forum.
} 
standardized and most variable of the four years, and is largely spent dabbling in electives and auditioning for residency rather than acquiring core knowledge. Prior to COVID-19 there was advocacy from some quarters to replace the fourth year with a focused transitional experience that would prepare students for their chosen field and potentially reduce the duration and cost of medical training (Alman et al. 2017). A related pre-pandemic concept was an individualized curriculum, which would allow students meeting competency milestones to complete medical school in less than four years or conversely might extend medical school for those needing more time (Frank et al. 2010).

Whether or not we view COVID-19 educational and licensing concessions as justifiable, we must acknowledge that they were implemented in a rush and not in the deliberate, research-driven manner anticipated by those promoting competencybased reform or fast-tracking efficiency. For better or worse, a shorter undergraduate medical experience accelerates a student's timeline for declaring a specialty and reduces opportunity to explore alternate career paths. In a time of crisis, an accelerated timeline with more prescriptive focus on career differentiation may be warranted to address critical health care capacity issues. But how will the medical education community know if and when we reach this critical need? Will there be signaling at the national level? Will this be left up to individual institutions based on volume of patients? In the context of a financially tolling pandemic, how might a reduction in length of undergraduate medical training affect the academic medical center's bottom line, including faculty salary and research?

As we enter the academic year 2020-2021, some students may want to get back to the pre-pandemic, four-year curriculum that provided a predictable calendar for summer research, licensure exams, and a generous amount of time to explore specialties and sample prospective residency programs (Wolf et al. 2014; Aldag 2020). Other students may favor the fast-paced, no frills approach to meeting minimum graduation and advancement standards that has been tolerated, at least temporarily, in the COVID-19 era. As the medical education community struggles to get back to business as usual, it must consider future scenarios where accelerated credentialing and needs-based special capacity building may be necessary. We must be better prepared for the next crisis.

\section{Technology in Undergraduate Medical Education}

Virtual education has been around for decades. Some professional degrees can be earned entirely online, while other programs supplement traditional in-person classes with online learning. Proper development of virtual classes requires a large upfront financial investment in technology and faculty development (Bartley and Golek 2004). In “The Inevitable Reimagining of Medical Education," published on the brink of the pandemic, Dr. Emanuel (2020) highlights a significant transformation taking place in medical education: namely, the pervasive presence of technology and its implications for this generation of medical students. He discusses the end of preclinical classroom instruction as students increasingly watch lectures 
remotely and supplement the medical school curriculum with online resources. He warns that in order to deliver online content effectively, changes in teaching need to occur, including transitioning from the classic one-hour didactic to six-to-twelveminute chunks of information. If transitioning to online courses, why limit students to the expertise of their home institution? Emanuel points out that students turn to online resources to learn from the best teachers on a given topic, so it behooves medical schools to leverage technology to allow students access to the best instruction in the basic sciences, even if taught by faculty at different institutions (Emanuel 2020).

This model--standardizing the preclinical curriculum and increasing access to excellent education through an online learning platform--emphasizes the prominence of technology in undergraduate medical education prior to COVID-19. Not surprisingly, there are two sides to this story. On one hand, students report benefits of remote learning such as setting their own schedules and being able to speed up a recording for efficiency or pause during a lecture to clarify a topic. On the other hand, faculty find it uninspiring to lecture to an empty auditorium, difficult to build rapport with students in a virtual space and exasperating to adapt to ever-changing online technology. COVID-19 has forced medical school faculty to become online instructors without formal training at a time when clinical tensions are on the rise, institutional budgets are stressed, and academic salaries are being cut (Colenda et al. 2020). The quality of on-the-fly course design in this setting is suspect. If undergraduate medical education continues in the direction of online learning in a prolonged pandemic, we can expect unbundling of the traditional faculty role and more investment in commercially available curricula and information systems and technology (Tucker and Neely 2010).

The COVID-19 pandemic has been a catalyst for a fragmented movement in online medical education. Some medical schools embraced online learning years ago, converting much of the preclinical curriculum to an online syllabus and implementing flipped classroom models ${ }^{6}$ for residual in-person teaching (Williams 2016). Other schools have only recently begun to make online lectures accessible to students, with continued clashes between faculty and students regarding in-person attendance. One example of this issue is provided by Dr. Kamran Mirza (2018) as he highlights the complex balance of teaching high quality lectures to nearly empty lecture halls in his piece in Reflective MedEd. At an institutional level, differences in philosophy, experience, and resources have impacted a medical school's readiness to adapt to online teaching during the pandemic. At the student level, differences in technical savvy, learning style, and availability of quiet study space and high-quality internet have impacted the individual's ability to adapt to online learning. Differences at the institutional and individual levels may exacerbate disparities in access to education, quality of education, and in career opportunities moving forward. Below

\footnotetext{
${ }^{6}$ Flipped classroom models focus on student engagement and active learning by delivering didactic content prior to interactive time with faculty with the goal of increased student participation through priming learning and preparing for application of new concepts.
} 
we examine technology's role before, during, and after COVID-19 in the preclinical and clinical learning environments and in the residency application process.

\section{Preclinical}

In general, the first eighteen to twenty-four months of medical school consist of basic science coursework, anatomy labs, and small group discussions and activities around doctoring skills such as gathering a patient history and performing a physical exam. Online learning can play an important role in the didactic elements of the preclinical years, allowing students flexibility with their time. Much of the supplemental educational content that prepares students for the USMLE Step 1 exam is delivered online and serves in part to standardize resources available at various institutions. Other aspects of a broad medical education--research experience, professional development, leadership opportunities, and so on--do not translate well to an online platform. It is difficult, if not impossible, to develop in these areas without face-to-face contacts with peers, community members, and medical and scientific professionals. The brick-and-mortar medical school offers preclinical students the venue to meet mentors who can nurture these skills. How will we train up future physician-scientists to fight the next pandemic if students don't enter a lab or collaborate with scientists during the preclinical years of medical school?

As the COVID-19 pandemic hit, the AAMC recommended that preclinical courses and educational activities be conducted remotely in accordance with social distancing guidelines (AAMC 2020a). In response, the preclinical curriculum was rapidly transitioned to online formats nationwide (Rose 2020). Online learning was no longer supplemental; it became the sole method of instruction. Because of the variability among medical schools and their fluency in technology, there were concerns about the quality of pre-recorded lectures from previous years and access to up-to-date school specific content. Small groups also convened online via remote meeting platforms, but it proved especially challenging to convert clinical skills sessions to remote learning formats. Moreover, as physician-educators were pulled onto the frontlines, many physician-led classes were canceled altogether, underscoring the constant tension between faculty's clinical and teaching responsibilities.

For preclinical students, a dilemma arising from COVID-19 lockdowns was the cancelation of USMLE Step 1 exams when numerous commercial Prometric testing sites closed their doors, as discussed in an Open Letter to the National Board of Medical Examiners (NBME) signed by over 2000 medical students (2020). A passing Step 1 score is a prerequisite to advancement into the clinical phase of medical school education. Looking for solutions to a growing issue affecting medical students across the country, the USMLE implemented "Phase One: Regional Testing Centers at Medical Schools," a plan to reschedule exams in alternate venues for some students (USMLE 2020). Medical schools selected to host the exams were large institutions with adequate technology and space, located in major metropolitan areas. Access to testing at these regional centers was limited by geography and social distancing guidelines. Additionally, the NBME announced that a shorter 
version of the Step 1 would be offered to those participating in event-based testing held at medical schools in July and August 2020. This would be accomplished by eliminating the usual $25 \%$ of questions in each exam that are experimental and unscored (USMLE 2020b). A swift backlash arose via social media calling for the reversal of this plan, citing that reducing the number of questions would create an unfair advantage to students taking the shorter version of the test at the makeshift regional centers (Frellick 2020). The NBME took notice and quickly cancelled the proposal, a rare reversal of course in response to consumer concern (USMLE 2020c). This is a powerful example of student advocacy amidst this time of great educational uncertainty and stress.

As students faced recurrent cancellation and rescheduling of USMLE Step 1 test dates, all the while preparing for these costly (Bhatnagar et al. 2019), and physically and emotionally demanding exams, we can hypothesize that access to technology was a differentiator of student experience. Students at prominent schools in geographically favored areas initially gained some advantage as their institutions had the technology and resources to offer USMLE Step 1 test administration. As we continue to explore increasing testing capacity via alternative testing platforms, we must examine the barriers that exist for medical students at a variety of institutions. This is a cautionary example of implementing technology-based solutions quickly without fully exploring short- and long-term implications for test-taking experience, parity, and outcomes.

\section{Clinical Learning Environment}

As students were pulled from clinical rotations in the spring of 2020, it was unclear how long this interruption in their learning and progression through medical school would last. With nearly every specialty having a national organization with some form of online learning curriculum, many institutions used online resources for completion of rotations and exams. Arguments against student presence in clinics and hospital wards included safety, utilization of scarce personal protective equipment (PPE), and cost of healthcare and interruption in education should a student fall ill with COVID-19 (American Medical Association 2020; Menon et al. 2020). As hands-on clinical learning paused, some schools turned to already implemented online resources while others utilized recorded material from years past. At institutions with the capacity to transition to virtual care, some students participated in telehealth visits or assisted in communicating with patients and families, both worthwhile learning activities. At other institutions, students were left without much guidance and searched for outside online elective opportunities in fear of not meeting graduation credit requirements. In late March 2020, LCME issued an update outlining approaches to salvaging the clinical curriculum deferred due to COVID19. Among these solutions was scouring a student's transcript to see if learning objectives had already been covered in prior clerkships. For third-year medical students, LCME recommended shortening clerkships and using virtual learning when appropriate to meet objectives (LCME 2020). Overall, access to technology and previous implementation of learning technology impacted the experiences of clinical 
students across the country. While virtual learning can provide some realistic clinical encounters, it is unlikely that virtual learning can adequately replace in-person hands-on clinical learning. For example, learning the intricacies of patient communication and technique of a female pelvic exam is not adequately addressed in video-based remote classrooms. Consider the much-studied example of simulation technology. It has been shown that simulation requires feedback, repetition, practice, and curriculum integration for educational success (Issenberg et al. 2005). However, in the midst of rapid implementation, not all components of successful integration can necessarily be met. While learners can be considered digital natives, there are practical and economic barriers such as access to stable internet connections, reliable computers, and suitable workspaces that also create challenges for some.

In addition to changes in the clinical phase of medical education, the question of assessment in this phase of education also arose. The USMLE Step 2 Clinical Skills (Step 2 CS) exam is an in-person practical exam that consists of multiple mock clinical encounters. With social distancing mandates, it became clear that administration of this exam would be severely limited. The USMLE's initial proposal to implement a virtual exam met with more backlash from the medical student community. Ultimately, USMLE governance announced that the Step 2 CS would be suspended for twelve, perhaps eighteen months (USMLE 2020d). Students' opposition to a virtual exam stemmed from the reality that telehealth is an emerging field, one with unique complexities. If students were to be assessed via a telehealth platform for a national board exam, the assessment would not correspond to the traditional clinical training of the majority. Students at institutions with progressive telehealth electives and online virtual case series would arguably have an unfair advantage. A similar disparity might also occur with location and availability of testing sites capable of supporting a virtual Step 2 CS exam. There are aspects of medical education, such as physical exam skills, that cannot be taught nor assessed virtually. The challenge is for the medical education community to prioritize the learning and assessment experiences that merit risks associated with social contact during a pandemic; these must be of high value to both trainees and future patients. As we continue to navigate the pandemic, we must anticipate consequences of not teaching or assessing particular medical skills in a traditional manner and how this will impact students today and their patients in years to come.

\section{Residency Application Process}

Each year senior medical students painstakingly write personal statements, create their Electronic Residency Application System (ERAS) profiles, and wait eagerly for interview invitations after applying to programs in the specialty of their choice. The process of applying, interviewing, and ranking programs is time consuming, and costly financially and emotionally (Berriochoa et al. 2018). With 38,376 medical students competing for residency in 2020, The Match ${ }^{7}$ affects an extraordinary number of individuals

\footnotetext{
7 The National Residency Matching Program (NRMP) also known as The Match, uses a mathematical algorithm to place applicants into residency positions. To make the matching algorithm work best for applicants, they create a rank order list in order of their true preferences. The system then matches candidates with unfilled residency spots.
} 
and their families. Students rely on word of mouth, mentor advice, and diligent research when applying to programs. But the in-person interview is likely critical to assessing "fit", which is cited as a key factor for ranking programs (National Resident Matching Program 2019). COVID-19 has considerably disrupted the application and interview process; students and programs alike must recognize challenges and advocate for solutions (Gabrielson et al. 2020). First, the application timeline was shifted to accommodate delays in testing and clerkship requirements as medical schools scrambled to get back on track for an on-time graduation in 2021. Second, away or "audition" rotations that many students complete at outside hospitals have been canceled to limit travel and reduce potential spread of COVID-19 (AAMC 2020b). Third, since interviews for the upcoming match season will be conducted via virtual platforms, access to technology and stage presence will be deciding factors.

Considering these changes, students scrambled to fill their schedules to ensure timely graduation, hunted for virtual away rotations, and began preparing for virtual interviews. Prior to the pandemic, students often used away rotations to signal both interest in a program and geographical preference, which increased the likelihood of interview offers (Kremer et al. 2020). However, without the ability to travel and rotate at other institutions, many students are concerned about how to signal these preferences. Regarding virtual interviews, factors such as the stability of internet connections, quality of web cameras, and the challenges of navigating a myriad of meeting platforms will need to be addressed. Some medical schools plan to assist students by providing office space, access to technology, and coaching on virtual interview techniques, but such support services are likely to vary significantly across the country. As applicants and programs prepare for a virtual interview season, there is growing concern that this match cycle will be even more distressing for applicants than in years past (Weiner 2020). Travel has always been an unpredictable variable in the interview process; now access to reliable technology will be the wild card. Applicants have a responsibility to be as well prepared as possible for virtual interviewing, but selection committees must also consider how a poor internet connection might impact clarity of communication and bias interviewers against an otherwise suitable candidate. Residency programs and applicants should be proactive in developing best practices for virtual interviewing.

As applicants turn to alternative sources such as Twitter and Instagram to learn about residency programs, the pandemic can be credited with breaking down some real and perceived barriers that existed in the application process prior to COVID19. Applicants can now "follow" programs, individual faculty, and residents online. One lasting impact of virtual interviewing may be an increased social media presence of residency programs, allowing applicants access to real-time, up-to-date information so they can make better decisions about where to apply and how to rank programs. Acknowledging that programs and applicants alike are subject to pandemic restrictions, there is a mutual responsibility to work towards quality improvement in this unprecedented process. When it comes to the right fit, a virtual match is risky for both applicants and programs. Will a completely virtual interview process lead to different outcomes for applicants who are unable to get a true "feel" for a program and the community in which they will work and live? Will this interview cycle lead to shifts in the culture and stability of residency programs? 


\section{Possible Medical Educational Outcomes of the COVID-19 Pandemic}

Over the course of the pandemic, medical students have witnessed rapid policy changes, ethical dilemmas over resource allocation, stressed hospital budgets, and even faculty and staff cuts. These changes in medical education will leave a lasting impression. The implicit way in which social and cultural aspects of an environment impart knowledge and mold behavior-known as the hidden curriculum-is especially pervasive in the house of medicine and can be the most powerful teacher in times of uncertainty (Alsubaie 2015; Wear 1998). In some ways, the COVID19 pandemic is one of the purest experiments in medical education's hidden curriculum: students are navigating a system without much explanation or guidance as practice and policy change almost daily. Although we are only a few months into the pandemic, both the healthcare system and medical education have been forced to adapt rapidly to shifting priorities and projections. The actions taken during this time signal to students what is important, who is important, and how to adapt during a global crisis. Sudden and dramatic changes to time-honored curricula, testing, and interview processes make us question how essential these traditions truly are to undergraduate medical education. Who are the winners and who are the losers when the rules of the game are altered? Should we return to the pre-pandemic ways of educating, assessing, and recruiting? Will students ever return to face-to-face didactics? Perhaps not, and maybe this makes way for innovations (Wayne et al. 2020). COVID-19 compels us to examine the utility and ethics of undergraduate medical educational practices that may benefit a majority but leave a portion of students disadvantaged. What lasting impact will COVID-19 have on the current cohort of trainees?

If COVID-19's legacy is a toxic hidden curriculum, then we might expect worsening of current discouraging trends in medical training and practice. For example, it is well established that empathy is important to the physician-patient relationship, yet medical students succumb to empathy erosion as they advance from preclinical to clinical training (Chen et al. 2007; Hojat et al. 2004, 2009; Newton et al. 2008). Some explanations for this erosion of empathetic capacity include: less autonomy upon entry to the clinical arena; lack of a consistent peer group typical of preclinical years; and a training environment characterized by human suffering and death (Vearrier 2020). As the pandemic continues to unfold, will it exacerbate empathy erosion or will it perhaps broaden trainees' understanding of population-based medicine, translational research, and utilitarian principles of healthcare ethics? Will students feel disenfranchised or will they speak up about their educational and professional fates as they did when confronted with sudden changes to USMLE test-taking procedures? The lessons that students learn will ultimately be shaped by the actions of the medical education community. Projecting into the future, medical students may observe shifting healthcare needs and alter their graduate medical education plans accordingly. Some may observe how subspecialty services were negatively impacted by the pandemic and think twice about further differentiating their careers.

Ultimately, through conscious engagement with learners, the medical education community has an opportunity to teach invaluable lessons about how to navigate a 
pandemic both clinically and academically. If another pandemic occurs or a second wave significantly impacts the status quo, students are likely to call upon this experience to inform how they care for patients and interact with peers as they progress into residency and beyond. The lessons learned, consciously and unconsciously, during this pandemic will shape medicine and medical education for generations. Students must continue advocating for learning opportunities and equitable assessments. Medical educators must invite students' perspectives and expertise as consumers of education when considering changes to curriculum, content delivery, testing, and the residency application process. Learning the "right" lessons from this pandemic and preventing disillusionment with the process of becoming a physician will be an ongoing challenge. It is our hope that both educators and students utilize COVID-19 as a catalyst for the reenvisioning of medical education.

Acknowledgement ES and SHG would like to acknowledge James Docherty, DO for his thoughtful comments and suggestions. Dr. Docherty, former Chair of the AMA Medical Student Section Committee on Medical Education and current Family Medicine PGY-1 at UHS-Wilson Medical Center, is passionate about medical education and advocating for Osteopathic medical students and residents. We value his insight and expertise.

Funding Not applicable.

Data Availability Not applicable.

\section{Compliance with Ethical Standards}

Conflicts of interest The authors declare that they have no conflict of interest.

\section{References}

Aldag, E. (2020). I'm a fourth-year medical student. I don't want to graduate early. AAMC News \& Insights. https://www.aamc.org/news-insights/i-m-fourth-year-medical-student-i-don-t-want-gradu ate-early.

Alman, B. A., Purtill, J. J., Pellegrini, V. D., \& Scoles, P. (2017). AOA Critical Issues The fourth year of medical school: Time for reassessment. The Journal of Bone and Joint Surgery. https://doi. org/10.2106/JBJS.16.01094.

Alsubaie, M. (2015). Hidden curriculum as one of current issues of curriculum. Journal of Education and Practice, 6(33), 125-128.

American Medical Association. (2020). AMA guiding principles to protect learners responding to COVID-19. https://www.ama-assn.org/delivering-care/public-health/ama-guiding-principles-prote ct-learners-responding-covid-19.

American Medical Association (AMA). (2019). AMA Reimaging Residency initiative. https://www.amaassn.org/education/improve-gme/ama-reimagining-residency-initiative.

Association of American Medical Colleges (AAMC). (2020a). Important guidance for medical students on clinical rotations during the coronavirus (COVID-19) outbreak. https://www.aamc.org/newsinsights/press-releases/important-guidance-medical-students-clinical-rotations-during-coronaviru s-covid-19-outbreak.

Association of American Medical Colleges (AAMC). (2020b). Medical student away rotations and inperson interviews for 2020-21 residency cycle. https://www.aamc.org/what-we-do/mission-areas/ medical-education/away-rotations-interviews-2020-21-residency-cycle. 
Association of American Medical Colleges (AAMC). (2019a). Statement for the record submitted to the House of Representatives Committee on small business: The doctor is out. Rising student loan debt and the decline of the small medical practice. https://www.aamc.org/system/files/c/1/498034-aamcs tatementtothehousesmallbusinesscommitteeregardingmedicaled.pdf.

Association of American Medical Colleges (AAMC). (2019b). Curriculum Reports. AAMC https://www. aamc.org/data-reports/curriculum-reports/interactive-data/academic-level-length-distribution-usand-canadian-medical-schools.

Association of Professors of Gynecology and Obstetrics (APGO). (2020). APGO receives AMA Reimagining Residency grant. https://www.apgo.org/transforming-the-ume-to-gme-transition/.

Bartley, S. J., \& Golek, J. H. (2004). Evaluating the cost effectiveness of online and face-to-face instruction. Educational Technology \& Society, 7(4), 167-175.

Beck, A. H. (2004). The Flexner report and the standardization of American medical education. JAMA. https://doi.org/10.1001/jama.291.17.2139.

Berriochoa, C., Reddy, C. A., Dorsey, S., Campbell, S., Poblete-Lopez, C., Schlenk, R., et al. (2018). The residency match: Interview experiences, postinterview communication, and associated distress. JGME. https://doi.org/10.4300/JGME-D-17-01020.1.

Bhatnagar, V., Diaz, S. R., \& Bucur, P. A. (2019). The cost of board examination and preparation: An overlooked factor in medical student debt. Cureus. https://doi.org/10.7759/cureus.4168.

Boyle, P. (2020). Medical school enrollments grow, but residency slots haven't kept pace. AAMC News \& Insights. https://www.aamc.org/news-insights/medical-school-enrollments-grow-residency-slots -haven-t-kept-pace.

Cangiarella, J., Gillespie, C., Shea, J. A., Morrison, G., \& Abramson, S. B. (2016). Accelerating medical education: A survey of deans and program directors. Medical Education Online, 21(1), 31794.

Chen, D., Lew, R., Hershman, W., \& Orlander, J. (2007). A cross-sectional measurement of medical student empathy. Journal of General Internal Medicine, 22(10), 1434-1438.

Colenda, C., Applegate, W., Reifler, B., \& Blazer, D. (2020). COVID-19: Financial stress test for academic medical centers. Academic Medicine. https://doi.org/10.1097/ACM.0000000000003418.

Duffy, T. P. (2011). The Flexner Report-100 years later. The Yale Journal of Biology and Medicine, 84(3), 269-276.

Emanuel, E. J. (2020). The inevitable reimagining of medical education. JAMA. https://doi.org/10.1001/ jama.2020.1227.

Flexner, A., Pritchet, H., \& Henry, S. (1910). Medical education in the United States and Canada bulletin number four (The Flexner Report). New York: The Carnegie Foundation for the Advancement of Teaching.

Flotte, T. R., Larkin, A. C., Fischer, M. A., Chimienti, S. N., DeMarco, D. M., Fan, P. Y., \& Collins, M. F. (2020). Accelerated graduation and the deployment of new physicians during the COVID-19 pandemic. Academic Medicine. https://doi.org/10.1097/acm.0000000000003540.

Frank, J. R., Snell, L. S., Cate, O. T., Holmboe, E. S., Carraccio, C., Swing, S. R., et al. (2010). Competency-based medical education: theory to practice. Medical Teacher. https://doi.org/10.3109/01421 59X.2010.501190.

Frellick, M. (2020). USMLE abandons plan for shorter tests after backlash. Medscape Medical News. https://www.medscape.com/viewarticle/932063.

Gabrielson, A. T., Kohn, J. R., Sparks, H. T., Clifton, M. M., \& Kohn, T. P. (2020). Proposed changes to the 2021 residency application process in the wake of COVID-19. Academic Medicine. https://doi. org/10.1097/ACM.0000000000003520.

Gallagher, T. H., \& Schleyer, A. M. (2020). "We signed up for this!"-student and trainee responses to the COVID-19 pandemic. New England Journal of Medicine. https://doi.org/10.1056/NEJMp20052 34.

Gardner, R. L., Cooper, E., Haskell, J., Harris, D. A., Poplau, S., Kroth, P. J., \& Linzer, M. (2019). Physician stress and burnout: the impact of health information technology. JAMIA. https://doi. org/10.1093/jamia/ocy145.

Gliatto, P., \& Karani, R. (2016). Viewpoint From 2 Undergraduate Medical Education Deans The residency application process: Working well, needs fixing, or broken beyond repair? JGME. https://doi. org/10.4300/JGME-D-16-00230.1.

Greysen, S. R., Chen, C., \& Mullan, F. (2011). A history of medical student debt: observations and implications for the future of medical education. Academic Medicine. https://doi.org/10.1097/ ACM.0b013e31821daf03. 
Hammoud, M. M., Standiford, T., \& Carmody, J. B. (2020). Potential implications of COVID-19 for the 2020-2021 residency application cycle. JAMA. https://doi.org/10.1001/jama.2020.8911.

Harvey, A. (2020). Covid-19: medical schools given powers to graduate final year students early to help NHS. BMJ (Clinical Research ed.), 2020(368), m1227.

Heudebert, G. R., \& Estrada, C. A. (2018). Are all teaching activities valued the same Their relative worth is in the eye of the beholder. Southern Medical Journal. https://doi.org/10.14423/SMJ.00000 00000000850 .

Hojat, M., Mangione, S., Nasca, T. J., Rattner, S., Erdmann, J. B., Gonnella, J. S., \& Magee, M. (2004). An empirical study of decline in empathy in medical school. Medical Education. https://doi.org/10. 1111/j.1365-2929.2004.01911.x.

Hojat, M., Vergare, M. J., Maxwell, K., Brainard, G., Herrine, S. K., Isenberg, G. A., et al. (2009). The devil is in the third year: A longitudinal study of erosion of empathy in medical school. Academic Medicine. https://doi.org/10.1097/ACM.0b013e3181b17e55.

Hughes, R. G., Barker, D. C., \& Reynolds, R. C. (1991). Are we mortgaging the medical profession? The New England Journal of Medicine. https://doi.org/10.1056/NEJM199108083250606.

Invitational Conference on USMLE Scoring (InCUS) (2019). Summary Report and Preliminary Recommendations from the Invitational Conference on USMLE Scoring (InCUS). USMLE. https://www. usmle.org/pdfs/incus/incus_summary_report.pdf.

Irby, D. M., Cooke, M., \& O’Brien, B. C. (2010). Calls for reform of medical education by the Carnegie Foundation for the Advancement of Teaching: 1910 and 2010. Academic Medicine, 85(2), 220-227.

Issenberg, S. B., MacGaghie, W. C., Petrusa, E. R., Lee Gordon, D., \& Scalese, R. J. (2005). Features and uses of high-fidelity medical simulations that lead to effective learning: A BEME systematic review. Medical Teacher, 27(1), 10-28.

Jolly, P. (2005). Medical school tuition and young physicians' indebtedness. Health Affairs (Project Hope). https://doi.org/10.1377/hlthaff.24.2.527.

Kerschner, J. (2020). The pandemic has disrupted medical school admissions. I urge you to apply anyway. AAMC News \& Insights. https://www.aamc.org/news-insights/pandemic-has-disrupted-medic al-school-admissions-i-urge-you-apply-anyway.

Khullar, D., Bond, A. M., \& Schpero, W. L. (2020). COVID-19 and the financial health of us hospitals. JAMA. https://doi.org/10.1001/jama.2020.6269.

Kremer, T. R., Kremer, M. J., Kremer, K. P., \& Mihalic, A. (2020). Predictors of getting a residency interview: Differences by medical specialty. Medical Education. https://doi.org/10.1111/medu.14303.

Li, J., Dow, W. H., \& Kariv, S. (2017). Social preferences of future physicians. Proceedings of the National Academy of Sciences of the United States of America. https://doi.org/10.1073/pnas.17054 51114.

Liaison Committee on Medical Education (LCME). (2020, March 20). LCME update on medical students, patients, and COVID-19: Approaches to the clinical curriculum. https://lcme.org/wp-content/ uploads/filebase/March-20-2020-LCME-Approaches-to-Clinical-Curriculum.pdf.

Martinez, A. (2020). Harvard faces \$5M class-action suit after coronavirus campus shutdown. The Boston Herald. https:/www.bostonherald.com/2020/05/20/harvard-faces-5m-class-action-suit-after -coronavirus-campus-shutdown/.

McOwen, K., Whelan, A., \& Farmakidis, A. (2020). Medical education in the United States and Canada. Academic Medicine. https://doi.org/10.1097/ACM.0000000000003497.

Menon, A., Klein, E. J., Kollars, K., \& Kleinhenz, A. (2020). Medical students are not essential workers: Examining institutional responsibility during the COVID-19 pandemic. Academic Medicine. https:// doi.org/10.1097/ACM.0000000000003478.

Miller, D. G., Pierson, L., \& Doernberg, S. (2020). The role of medical students during the COVID-19 pandemic. Annals of Internal Medicine. https://doi.org/10.7326/M20-1281.

Mirza, K. (2018). My classroom is empty: Is that a problem? Reflective MedEd. https://reflectivemeded .org/2018/05/01/my-classroom-is-empty-is-that-a-problem/.

Murphy, B. (2020). USMLE Step 1 moves to pass-fail: Answers to 7 key questions. https://www.amaassn.org/residents-students/usmle/usmle-step-1-moves-pass-fail-answers-7-key-questions.

National Resident Matching Program (NRMP) (2019). Results of the 2019 NRMP applicant survey by preferred specialty and applicant type. https://mk0nrmp3oyqui6wqfm.kinstacdn.com/wp-content/ uploads/2019/06/Applicant-Survey-Report-2019.pdf.

Newton, B. W., Barber, L., Clardy, J., Cleveland, E., \& O'Sullivan, P. (2008). Is there hardening of the heart during medical school? Academic Medicine, 83(3), 244-249. 
Open letter to the NBME regarding Step exam administration during the COVID-19 pandemic. (2020). https://docs.google.com/forms/d/e/1FAIpQLSfGKnUgT-hczz6ws7Wz1ijrnTkj8rKhqJnjWJ42tya6T $\mathrm{mBtcg} /$ viewform.

Pettett, G. (2011). The economics of medical education: A dismal science with a dismal prognosis. Missouri Medicine, 108(5), 313-315.

Rose, S. (2020). Medical student education in the time of COVID-19. JAMA. https://doi.org/10.1001/ jama.2020.5227.

Rubin, E. J., Harrington, D. P., Hogan, J. W., Gatsonis, C., Baden, L. R., \& Hamel, M. B. (2020). The urgency of care during the Covid-19 pandemic - Learning as we go. The New England journal of medicine. https://doi.org/10.1056/NEJMe2015903.

Thomas, B. (2019). Free medical school tuition: Will it accomplish its goals? JAMA. https://doi. org/10.1001/jama.2018.19457.

Tolsgaard, M. G., Cleland, J., Wilkinson, T., \& Ellaway, R. H. (2020). How we make choices and sacrifices in medical education during the COVID-19 pandemic. Medical teacher. https://doi. org/10.1080/0142159X.2020.1767769.

Tucker, J., \& Neely, P. (2010). Unbundling faculty roles in online distance education programs. International Review of Research in Open and Distributed Learning. https://doi.org/10.19173/irrodl.v11i2 .798 .

United States Medical Licensing Exam (USMLE). (2020a). Pilot begins next week for phase one: Regional testing centers at medical schools. https://www.usmle.org/announcements/default.aspx.

United States Medical Licensing Exam (USMLE). (2020b). Phased approach to expand USMLE testing: Event-based testing update. https://covid.usmle.org/announcements/covid-19-update-a-phase d-approach-for-expanding-step-1-step-2-ck-and-step-3-testing/.

United States Medical Licensing Exam (USMLE). (2020c). USMLE to administer standard length forms at all sites. https://covid.usmle.org/announcements/usmle-administer-standard-length-forms-all-sites

United States Medical Licensing Exam (USMLE). (2020d). Step 2 CS is temporarily suspended https:// www.usmle.org/step-2-cs/\#: :text=USMLE\%20Step $\% 202 \% 20$ CS\%20is,be $\% 20$ reported $\% 20$ on $\% 20$ USMLE\%20transcripts.

Vearrier, L. (2020). Enlightened self-interest in altruism (ESIA). HEC Forum. https://doi.org/10.1007/ s10730-020-09406-8.

Vearrier, L., \& Henderson, C. M. (2021) Utilitarian principlism as a framework for crisis healthcare ethics. HEC Forum. https://doi.org/10.1007/s10730-020-09431-7.

Wayne, D. B., Green, M., \& Neilson, E. G. (2020). Medical education in the time of COVID-19. Science Advances. https://doi.org/10.1126/sciadv.abc7110.

Wear, D. (1998). On white coats and professional development: The formal and the hidden curricula. Annals of Internal Medicine, 129(9), 734-737.

Weiner, S. (2020). Applying to residency is tough even in normal times. The pandemic isn't helping. AAMC News \& Insights. https://www.aamc.org/news-insights/applying-residency-tough-evennormal-times-pandemic-isn-t-helping.

Weissbart, S. J., Kim, S. J., Feinn, R. S., \& Stock, J. A. (2015). Relationship between the number of residency applications and the yearly match rate: Time to start thinking about an application limit? Journal of Graduate Medical Education, 7(1), 81-85.

Whalen, J. P. (1987). Participation of medical students in the care of patients with AIDS. Journal of Medical Education, 62(1), 53-54.

Whelan, A., Prescott, J., Young, G., Catanese, V., \& McKinney, R. (2020). Guidance on medical students' participation in direct in-person patient contact activities. AAMC https://www.aamc.org/syste m/files/2020-08/meded-August-14-Guidance-on-Medical-Students-on-Clinical-Rotations.pdf.

Williams, D. E. (2016). The future of medical education: Flipping the classroom and education technology. Ochsner J., 16(1), 14-15.

Winter, T. H., \& McGee-Tubb, M. S. (2020). COVID-19 tuition and fees lawsuits: Defending university practices and defeating class claims. The National Law Review, 10(249), 1-4.

Wolf, S. J., Lockspeiser, T. M., Gong, J., \& Guiton, G. (2014). Students' perspectives on the fourth year of medical school: A mixed-methods analysis. Academic Medicine. https://doi.org/10.1097/ ACM.0000000000000183.

Woolhandler, S., \& Himmelstein, D. U. (2014). Administrative work consumes one-sixth of US physicians' working hours and lowers their career satisfaction. Journalism \& Mass Communication Quarterly. https://doi.org/10.1177/107769900207900102. 
Publisher's Note Springer Nature remains neutral with regard to jurisdictional claims in published maps and institutional affiliations. 